\title{
Omega 3 polyunsaturated fatty acid improves spatial learning and hippocampal Peroxisome Proliferator Activated Receptors (PPARa and PPAR $\gamma$ ) gene expression in rats
}

\author{
Toktam Hajjar ${ }^{1 \dagger}$, Goh Y Meng ${ }^{1,2^{*}+}$, Mohamed A Rajion ${ }^{1 \dagger}$, Sharmili Vidyadaran ${ }^{3 \dagger}$, Fauziah Othman ${ }^{4 \dagger}$,
} Abdoreza S Farjam ${ }^{1,2+}$, Tan $\mathrm{A} \mathrm{Li}^{1+}$ and Mahdi Ebrahimi ${ }^{1+}$

\begin{abstract}
Background: This study examined the effects of dietary polyunsaturated fatty acids (PUFA) as different n-6: n-3 ratios on spatial learning and gene expression of peroxisome- proliferator-activated receptors (PPARs) in the hippocampus of rats. Thirty male Sprague-Dawley rats were randomly allotted into 3 groups of ten animals each and received experimental diets with different n-6: n-3 PUFA ratios of either 65:1, 22:1 or 4.5:1. After 10 weeks, the spatial memory of the animals was assessed using the Morris Water Maze test. The expression of PPARa and PPARY genes were determined using real-time PCR.
\end{abstract}

Results: Decreasing dietary n-6: n-3 PUFA ratios improved the cognitive performance of animals in the Morris water maze test along with the upregulation of PPARa and PPARY gene expression. The animals with the lowest dietary n-6: n-3 PUFA ratio presented the highest spatial learning improvement and PPAR gene expression.

Conclusion: It can be concluded that modulation of n-6: n-3 PUFA ratios in the diet may lead to increased hippocampal PPAR gene expression and consequently improved spatial learning and memory in rats.

Keywords: PUFA, n-6: n-3 PUFA ratio, Spatial learning, PPAR, Cognitive function

\section{Background}

The $n-3$ polyunsaturated fatty acids (PUFA) play an important role in cellular functioning and normal brain cognitive function development including learning and memory $[1,2]$. The studies have shown that low dietary $n$ 3 PUFA and low plasma docosahexaenoic acid (DHA; 22:6 n-3) concentrations decreased n-3 PUFA in the brain and in turn resulted in behavioral defects [3,4]. It is known that high dietary saturated fat lead to hypercholesterolemia, and high blood pressure, causing atherosclerosis [5]. Hypertension and atherosclerosis cause dysfunction in the

\footnotetext{
* Correspondence: ymgoh@vet.upm.edu.my

${ }^{\dagger}$ Equal contributors

'Department of Veterinary Preclinical Sciences, Universiti Putra Malaysia, 43400 UPM, Serdang, Selangor, Malaysia

${ }^{2}$ Institute of Tropical Agriculture, Universiti Putra Malaysia, 43400 UPM,

Serdang, Selangor, Malaysia

Full list of author information is available at the end of the article
}

blood brain barrier function, and ischemia in the brain which may lead to the cognitive impairment [6-8]. On the contrary, recent studies have shown that PUFA improve spatial memory $[5,9]$. The PUFA supplementation contributes to modulation of membrane composition, fluidity and selective permeability, cellular signaling and regulation of gene expression [10].

The current diets are generally deficient in $n-3$ fatty acids and abundant in n-6 [11]. The n-3 fatty acids increase membrane fluidity by replacing $n-6$ fatty acids and cholesterol from the membrane [12] maintaining an optimal membrane fluidity which is obligatory for neurotransmitter binding and signaling within the cell [13]. The $n-3$ PUFA incorporated into the neuron membrane also increase synaptic protein expression, strengthening the hippocampal synaptic plasticity [3]. This is modulated by transcription factors such as peroxisome proliferatoractivated receptors (PPARs) [14]. 
The PPARs play a critical physiological role as lipid sensors and regulators of lipid metabolism [15]. The PPAR $\alpha$ and PPAR $\gamma$ are the key messengers responsible for the translation of nutritional stimuli into changes for the expression of genes, particularly genes involved in lipid metabolism [16]. Fatty acids can activate and induce the enzymes of the peroxisomal $\beta$-oxidation pathway at the transcriptional level by the mediation of ligand-activated transcription factors PPARs $[17,18]$. The PPAR $\alpha$ plays an important role in the regulation of acetylcholine biosynthesis that contributes to cognitive function $[14,19]$, and PPAR $\gamma$ has a prominent role in the regulation of central nervous system (CNS) inflammation and neuroprotection [20,21] leading to improvement in cognitive performance [20,22]. These findings indicated that cognitive performance can be enhanced through PPAR nuclear receptors [23]. However, the modulation effects of different dietary n6: n-3 ratio on PPAR genes at the hippocampal level is still not well understood. Therefore, the present study aimed to examine the hypothesis that a reduction in dietary n-6: n-3 PUFA ratios may alter the hippocampal PPAR gene expression and consequently spatial memory.

\section{Results}

\section{Behavioral test}

\section{Spatial acquisition}

On the first trial of acquisition, no difference was found in escape latency among the three groups. The relative escape latency of all groups gradually declined over the training period $(P<0.05)$ (Figure 1$)$. On the first day of the second trial, the LMO and HMO rats had a shorter relative escape latency compared with CTRL $(P<0.05)$.
On day 5, the HMO rats spent the shortest time to find the platform $(P<0.05)$.

\section{Probe trial}

The HMO rats swam for a higher percentage of time in the target quadrant (SW) compared with the other quadrants $(P<0.05)$ (Figure 2$)$. Conversely, the CTRL rats relied on random probability to locate the platform and spent a similar percentage of time in all quadrants $(P>0.05)$.

\section{Gene expression}

The effects of different levels of menhaden fish oil and soybean oil supplementation on PPAR gene expression are shown in Figure 3 and 4. The PPAR $\alpha$ (Figure 3) and PPARY (Figure 4) genes showed a higher level of expression in the LMO and HMO groups compared with the CTRL group $(P<0.05)$. In other words, the reduction of dietary n-6: n-3 PUFA ratios upregulated the PPAR gene expression in the hippocampus.

\section{Discussion}

The aim of the present study was to clarify whether the n3 fatty acids could affect the expression of mRNA encoding for PPARs in the memory-related brain region, the hippocampus. Previous studies have reported that dietary PUFA were able to increase PPAR $\alpha$ and PPAR gene expression in different tissues. For instance, the expression of PPAR $\alpha$ genes in human macrophages tends to increase following incubation with n-3 fatty acids [24]. The studies have also reported that the increasing dietary PUFA will upregulate PPAR $\alpha$ and PPAR $\gamma$ expression after lipopolysaccharide (LPS)-induced PPARs downregulation in the spleen, liver and bursa of chickens [25].

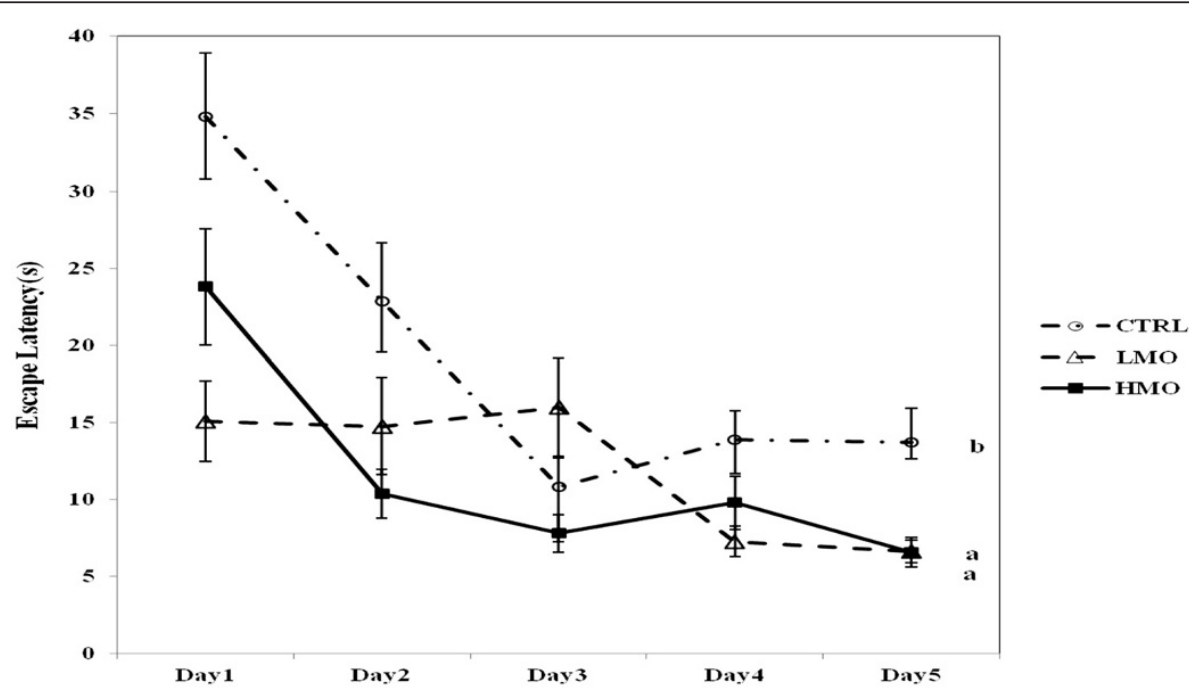

Figure 1 Escape latency over the training period $(\mathbf{n}=\mathbf{1 0})$. ${ }^{a, b}$ Lines with different alphabetic notation differ significantly at $P<0.0 .5$. CTRL, LMO and $\mathrm{HMO}$ refer to groups of rats fed with control, low menhaden oil, and high menhaden oil, respectively. 


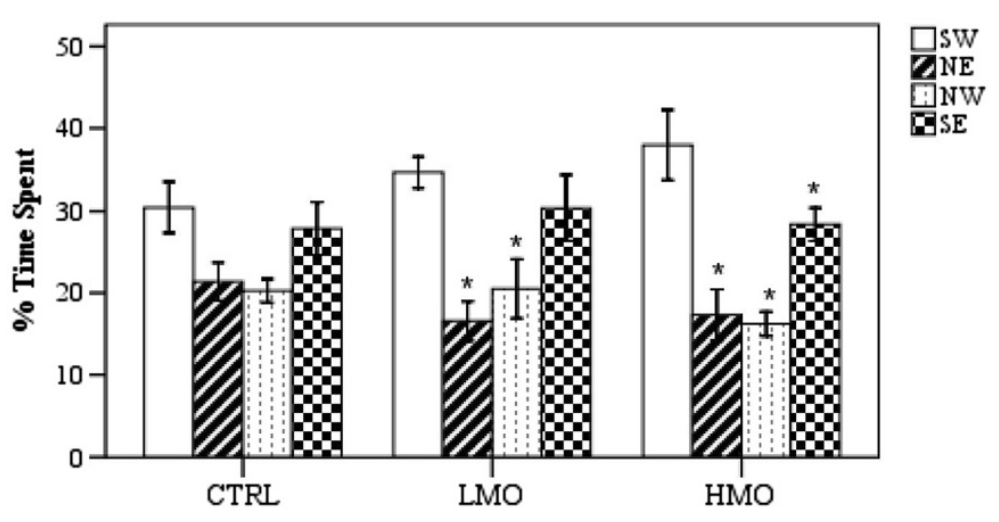

Figure 2 Relative time spent in each quadrant in the probe test $(\mathbf{n}=10)$. Significant differences from the mean values of the target quadrant $(S W)$ in each group were indcated by * $(P<0.05)$. Error bar shows $\pm 1 S E$, CTRL, LMO and HMO refer to group of rats fed with control, low menhaden oil (high $n-6: n-3$ ), and high menhaden oil (low n-6: n-3), respectively. SW: south-west, NE: north-east, NW: north-west, SE: south east.

In this study, the results demonstrated that diets with low n-6: n-3 PUFA ratios improved spatial memory and upregulated the hippocampal PPAR $\alpha$ and PPAR gene expression. This is evident in the performance of the unsupplemented CTRL group in the probe trial. The CTRL group had difficulties recalling the location of the escape platform from the most recent training session. As a result they depended on random chance to locate the platform and spent a similar percentage of time in all quadrants. The probe trial is typically used to assess reference memory in test subjects, and administered immediately after a training or acquisition session [26]. Current results also indicated differences between the expression of PPAR $\alpha$ and PPAR $\gamma$ genes in the rats supplemented with two different n-6: n-3 PUFA ratios. In fact, the level of expression of these genes was increased by the reduction of $n-6: n-3$ fatty acid ratios. The PPAR $\alpha$ and PPARy are expressed widely in the CNS, especially



Figure 3 Expression of PPARa in the brain of treatment groups compared to CTRL group. Triplicates of real-time PCR were performed for each sample. Values were normalized with a housekeeping gene, $\beta$-actin. Then, treated samples were expressed relative to gene expression of CTRL group. Statistical analysis was perfomed using a Student's t test. Values are means \pm 1 standard error bar. Values indicated by * show significant differences compared with the CTRL group $(P<0.05)$. CTRL: control, LMO: low menhaden oil, HMO: high menhaden oil. 




Figure 4 Expression of PPARY in the brain of treatment groups compared to CTRL group. Triplicates of real-time PCR were performed for each sample. Values were normalized with a housekeeping gene, $\beta$-actin. Then, treated samples were expressed relative to gene expression of CTRL group. Statistical analysis was performed using a Student's $t$ test. Values are means \pm 1 standard error bar. Values indicated by * show significant differences compared with the CTRL group ( $P<0.05)$. CTRL: control, LMO: low menhaden, HMO: high menhaden oil.

in the brain areas involved in learning and memory, such as the hippocampus [27]. The anti-inflammatory and anti-apoptotic role of PPARs could play important functions in the improvement of the mental ability of the brain [14]. Other possible mechanisms underlying the links between these changes in PPARs expression and the learning process may be related to their transcriptional role in synaptic plasticity and long term potentiation (LTP). The involvement of these transcription factors in protein synthesis are relevant to the synaptic mechanisms that mediate the formation of long term memory. Transcription is an essential step for long term synaptic plasticity and transcription factors play an important role in LTP through molecular alterations which facilitate long term synaptic plasticity and memory formation $[28,29]$. Indeed, participation of the transcription factor PPARs in the consolidation of memory in the rat's hippocampus results in the improved performance in the spatial memory task. The PPARs have specific functions in regulating the expression of genes involved in neurotransmission, and therefore play important roles in complex processes including learning and memory formation [14]. They played an essential role in regulating gene encoding for neurotransmitter receptors, synaptic protein and enzymes involved in neurotransmitter metabolism or release [14]. The n-3 PUFA stimulate PPAR target gene expression such as lipoprotein lipase (LPL), fatty acid transport protein (FTTP) and acyl-CoA synthase (ACS), thus enhancing the effects of n-3 PUFA on brain function [29].

In summary, the study showed that there is a relationship between gene expression of PPARs and feeding with $\mathrm{n}-3$ fatty acids. The increase in n-3 PUFA of the brain may lead to increased PPAR gene expression. It also suggests that PPAR $\alpha$ and PPAR $\gamma$ as transcription factors may affect the expression of synaptic proteins leading to increased synaptic plasticity and improved spatial memory in animals supplemented with higher n-3 PUFA, where the ratio of $n-6: n-3$ of $4.5: 1$ was more effective than the ratio of 22:1.

\section{Conclusions}

In this study, it was shown that the n-3 PUFA supplementation resulted in differences in PPAR $\alpha$ and PPAR $\gamma$ expressions in the brain. In conclusion, PPAR $\alpha$ and PPAR $\gamma$ genes displayed a tendency to be expressed at a higher level in rats fed diets with a lower n-6: n-3 PUFA ratio and may be able to improve spatial learning and memory. Further studies should be done using relatively pure $n-6$ and $n-3$ fatty acids to confirm these findings, and confirm that the lower $n-6: n-3$ ratios can improve learning and memory and increase the expression of 
PPARs in the hippocampus. Further investigations should be carried out to examine the effects of $n-6: n-3$ ratios on the gene expression in other brain regions such as the prefrontal cortex, amygdala and others.

\section{Methods}

\section{Animals and diets}

Thirty individually housed, three-week old male Sprague-Dawley rats were allotted randomly into three groups of ten animals each namely the control (CTRL), low menhaden oil (LMO), and high menhaden oil (HMO) groups. They were maintained under a light/ dark cycle $12 / 12 \mathrm{~h}$ at constant temperature $\left(25 \pm 2^{\circ} \mathrm{C}\right)$ and humidity (50-60\%). The experiment was approved by the Institutional Animal Care and Use Committee (IACUC) of the Faculty of Veterinary Medicine, Universiti Putra Malaysia. After two weeks of adaptation, the rats were fed for 12 weeks as follows: CTRL, standard pellet enriched with $7 \%(\mathrm{w} / \mathrm{w})$ of butter; LMO, standard pellet enriched with $1 \%(\mathrm{w} / \mathrm{w})$ fish oil $+6 \%(\mathrm{w} / \mathrm{w})$ soybean oil; HMO, standard pellet enriched with $3.5 \%$ $(\mathrm{w} / \mathrm{w})$ fish oil $+3.5 \%(\mathrm{w} / \mathrm{w})$ soybean oil (Table 1). All diets were prepared fresh and fed to the animals once daily.

\section{Morris water maze}

At the end of the $10^{\text {th }}$ week, all rats were assessed for their spatial memory performance using the Morris Water Maze (MWM) test of Vorhees and Williams [26]. The swimming pool used for the test was $120 \mathrm{~cm}$ in diameter. The pool was filled to a height of $30 \mathrm{~cm}$ with water at $23^{\circ} \mathrm{C}\left( \pm 1^{\circ} \mathrm{C}\right)$. The escape platform was fixed in a permanent position $2 \mathrm{~cm}$ under the water surface. The water tank was located in an experimental room and spatial reference cues (circle, rectangle, and triangle) around the pool remained fixed on the tank during the test. The pool was divided into four quadrants, namely zone NW (north-west), NE (north-east), SW (south-west) and SE (south-east). The quadrant housing the escape platform was defined as the target quadrant. A digital video camera (DCR-SR47; Sony Corporation, Tokyo, Japan) was installed two meters above the pool and was used to record the animals' performance. The test was carried out in two phases as described below.

\section{Spatial acquisition}

This trial evaluated the learning ability indicated by the decreasing escape latencies. All rats included in this study were selected from those who have passed the swimming ability test, had no physical defects or motor function deficits that could confound the study. The rats were trained in MWM for 5 consecutive days using a 4-trial-per-day regime. In each trial, the rats were placed in the pool facing the inner wall of the tank at one of four random starting points, such that the four positions
Table 1 Fatty acid profile of experimental diets (\% of total identified fatty acids)

\begin{tabular}{|c|c|c|c|}
\hline \multirow[b]{2}{*}{ Fatty acid } & \multicolumn{3}{|c|}{ Experimental diets } \\
\hline & CTRL & LMO & HMO \\
\hline Caprylic Acid (8:0) & 0.70 & 0.17 & 0.13 \\
\hline Capric Acid (10:0) & 0.87 & 0.13 & 0.09 \\
\hline Lauric Acid (12:0) & 6.05 & 0.06 & 0.05 \\
\hline Myristic Acid (14:0) & 4.66 & 1.26 & 2.82 \\
\hline Palmitic Acid (16:0) & 28.11 & 15.16 & 16.47 \\
\hline Palmitoleic Acid (16:1) & 0.84 & 1.53 & 3.93 \\
\hline Stearic Acid (18:0) & 6.77 & 4.18 & 4.84 \\
\hline Oleic Acid (18:1n-9) & 29.59 & 20.35 & 26.85 \\
\hline Linoleic Acid (18:2n-6) & 17.78 & 40.37 & 31.94 \\
\hline Linolenic Acid (18:3n-3) & 0.28 & 0.37 & 0.27 \\
\hline Arachidic Acid (20:0) & 1.51 & 2.09 & 2.39 \\
\hline Arachidonic Acid (20:4n-6) & 0.15 & 0.13 & 0.29 \\
\hline Eicosapentaenoic acid (20:5n-3) & nd & 0.92 & 3.40 \\
\hline Docosapentaenoic acid (22:5n-3) & nd & 0.20 & 1.13 \\
\hline Docosahexaenoic acid (22:6n-3) & nd & 0.45 & 2.46 \\
\hline Total SFA & 50.19 & 24.43 & 27.98 \\
\hline Total UFA & 49.81 & 75.57 & 72.02 \\
\hline Total MUFA & 31.54 & 33.03 & 32.29 \\
\hline Total n-3 PUFA & 0.28 & 1.94 & 7.26 \\
\hline Total n-6 PUFA & 17.99 & 40.59 & 32.47 \\
\hline$n-6: n-3$ & 64.25 & 20.92 & 4.47 \\
\hline UFA:SFA & 0.99 & 3.09 & 2.57 \\
\hline PUFA:SFA & 0.36 & 1.74 & 1.42 \\
\hline
\end{tabular}

CTRL: control, LMO: low menhaden oil, HMO: high menhaden.

nd: not detected.

Total SFA: sum of 8:0, 10:0, 12:0, 14:0, 16:0, 18:0 and 20:0

Total UFA: sum of $16: 1,18: 1 n-9,18: 2 n-6,20: 4 n-6,18: 3 n-3,20: 5 n-3,22: 5 n-3$ and 22:6n-3.

Total MUFA: sum of $16: 1$ and 18:1n-9.

Total n-3PUFA: sum of 18:3n-3, 20:5n-3, 22:5n-3 and 22:6n-3.

Total n-6PUFA: sum of $18: 2 n-6,20: 4 n-6$

$n-6: n-3$ :Total n-6 PUFA: (sum of 18:2n-6, 20:4n-6)/ Total n-3 PUFA: (sum of $18: 3 n-3,20: 5 n-3,22: 5 n-3$ and 22:6n-3).

were used each day. The rats were given 1 minute to locate the hidden platform, which is in the middle of the SW quadrant. Once the rat located the escape platform it was permitted to remain on it for 10 seconds. If the animals failed to find the platform, they were directed onto the platform. The escape latency was recorded by the video camera and analyzed by ANY-maze video tracking system software (Stoelting Co., USA).

\section{Probe trial}

To estimate spatial memory retention, a probe trial was performed 1 day after the last acquisition day. In this phase, the platform was removed from the pool and rats were allowed to swim for 1 minute. The relative time spent by each rat in each quadrant was recorded and 
analyzed. The spatial accuracy of the animal is represented by the time the animal spent on looking for the platform in the target quadrant where the platform used to be during the acquisition phase.

\section{Fatty acid analysis}

Total lipids from the experimental diets were extracted according to the methods described by [30] and modified by [31]. The experimental dets approximately $2 \mathrm{~g}$ were mixed with $40 \mathrm{ml}$ of chloroform-methanol $(2: 1, \mathrm{v} / \mathrm{v})$ containing butylated hydroxytoluene as antioxidant. Then, fatty acids methyl esters (FAME) were prepared using $0.66 \mathrm{~N}$ potassium hydroxide $(\mathrm{KOH})$ in methanol and $14 \%$ methanolic boron trifluoride $\left(\mathrm{BF}_{3}\right)$ (Sigma Chemical Co. St. Louis, Missouri, USA). The FAME were separated with an Agilent 6890A Series GC system (Agilent Technologies, Palo Alto, CA, USA) using a $30 \mathrm{~m} \times 0.25 \mathrm{~mm}$ ID $(0.20 \mu \mathrm{m}$ film thickness $)$ Supelco SP2330 capillary column (Supelco, Inc., Bellefonte, PA, USA). The fatty acid proportions are expressed as percentage of total identified fatty acids. One microlitre of FAME was injected by an auto sampler into the chromatograph, equipped with a split/splitless injector and a flame ionization detector (FID) detector. The injector temperature was programmed at $250^{\circ} \mathrm{C}$ and the detector temperature was $300^{\circ} \mathrm{C}$. The column temperature program initiated runs at $100^{\circ} \mathrm{C}$, for $2 \mathrm{~min}$, warmed to $170^{\circ} \mathrm{C}$ at $10^{\circ} \mathrm{C} / \mathrm{min}$, held for $2 \mathrm{~min}$, warmed to $200^{\circ} \mathrm{C}$ at $7.5^{\circ} \mathrm{C} / \mathrm{min}$, and then held for $20 \mathrm{~min}$ to facilitate optimal separation. Identification of fatty acids was carried out by comparing relative FAME peak retention times of samples to standards obtained from Sigma (St. Louis, MO, USA).

\section{Gene expression}

Following the behavioral test, all rats were anesthetized with ketamine-xylazine $(80 \mathrm{mg} / \mathrm{kg}$ and $10 \mathrm{mg} / \mathrm{kg}$ intra peritoneal, respectively). The brain was quickly excised and the hippocampus immediately dissected, frozen in liquid nitrogen and stored at $-80^{\circ} \mathrm{C}$ until RNA extraction. Total RNA was extracted from $100 \mathrm{mg}$ of frozen tissue using the RNeasy ${ }^{\circledR}$ lipid tissue mini kit (Qiagen, Hilden, Germany) and DNase digestion was completed during RNA purification using the RNase-Free DNase set (Qiagen, Hilden, Germany) according to the manufacturer's instructions. Total RNA integrity was checked by agarose gel electrophoresis and purity was determined by the 260/280 NM ratio of absorbance readings. Purified total RNA $\left(\begin{array}{ll}1 & \mu g\end{array}\right)$ was reverse transcribed using a Quantitect ${ }^{\circledR}$ reverse transcription kit (Qiagen, Hilden, Germany) in accordance with the manufacturer's recommended procedure. Real-time PCR was performed on a RotorGene 3000 Real-Time PCR Detection System (Corbett
Research, Sydney, Australia) using Quantifast ${ }^{\circledR}$ SYBR green PCR I kit (Qiagen, Hilden, Germany). The sequences of primers were as follows: $\beta$-actin, sense: $5^{\prime}$-CTGTGT TGTCCCTGTATGCC-3' antisense: $5^{\prime}$-TAGATGGGCA CAGTGTGGGT-3'; PPAR $\alpha$, sense: 5'-CGACAAGTGTG ATCGAAGCTGCAAG-3' antisense: $5^{\prime}$-GTTGAAGTT CTTCAGGTAGGCTTC-3'; PPAR $\gamma$, sense: $5^{\prime}$-GCGGA GATCTCCAGTGATATC-3' antisense: $5^{\prime}$-TCA GCGAC TGGGACTTTTCT- $3^{\prime}$. The $\beta$-actin was used as the reference gene to normalize the tested genes. The sequence specificity of each primer pair was confirmed using BLAST, and all primers were purchased through $1^{\text {st }}$ BASE oligonucleotide synthesis (Singapore). Each reactions $(25 \mu \mathrm{l})$ were contained $12.5 \mu \mathrm{l}$ SYBR green PCR mix, $1 \mu$ l diluted cDNA, $0.3 \mu \mathrm{M}$ each of forward and reverse primers and RNase free water. Target genes were amplified through the following thermocycling program: $95^{\circ} \mathrm{C}$ for $10^{\prime}, 40 \mathrm{PCR}$ cycles at $95^{\circ} \mathrm{C}$ for $30^{\prime \prime}, 60^{\circ} \mathrm{C}$ for $20^{\prime \prime}$ and $72^{\circ} \mathrm{C}$ for $20^{\prime \prime}$. Fluorescence was measured at every $15^{\prime \prime}$ to construct the melting curve. The specificity of the amplification product was further verified by electrophoresis on a $0.8 \%$ agarose gel and by DNA sequencing. A real-time PCR was conducted for each primer pair in which cDNA samples were substituted with $\mathrm{dH}_{2} \mathrm{O}$ to verify that exogenous DNA was not present. Additionally, $1 \mu \mathrm{g}$ of RNA isolated by the procedure described above were substituted for cDNA in a realtime PCR reaction to confirm that there were no genomic DNA contaminants in the RNA samples. Both negative controls showed no amplification after 40 cycles. Efficiency of amplification was determined for each primer pair using serial dilutions. The relative expression of each gene, normalized to the reference gene, between treated and control samples were calculated using the relative expression software tool (REST) [32].

\section{Statistical analysis}

The data acquired for acquisition \& probe trials in MWM was analyzed using a two-way repeated measure ANOVA. Maze performance parameters were compared across attempts, days, and consequently across treatment groups. Significantly different means were then elucidated using the Bonferroni test. All tests were conducted at $95 \%$ confidence level. Gene expression was calculated using the formula below and expressed as fold change between treatment and control groups.

$$
\text { Ratio }=\frac{\left(E_{\text {target }}\right)^{\Delta C T_{\text {target }}(\text { Control-Treatment })}}{\left(E_{\text {reference }}\right)^{\Delta C T_{\text {reference }}(\text { Control-Treatment })}}
$$

Gene expression data were checked for normality and homogeneity of variance using SPSS statistical software. Differences in mean values between the treatments and control were tested using one way ANOVA. Data were 
expressed as Means \pm SE. Differences of $P<0.05$ were considered to be significant.

\section{Competing interests}

The authors declare that they have no competing interests.

\section{Authors' contributions}

All authors conceived the study, participated in the experiment design and drafted the manuscript.

\section{Acknowledgement}

This study was supported by the Research University Grant Scheme (Vote No. 91734), Universiti Putra Malaysia.

\section{Author details}

'Department of Veterinary Preclinical Sciences, Universiti Putra Malaysia, 43400 UPM, Serdang, Selangor, Malaysia. ${ }^{2}$ Institute of Tropical Agriculture, Universiti Putra Malaysia, 43400 UPM, Serdang, Selangor, Malaysia. ${ }^{3}$ Department of Pathology, Faculty of Medicine and Health Sciences, Universiti Putra Malaysia, Serdang, Selangor, Malaysia. ${ }^{4}$ Department of Human Anatomy, Faculty of Medicine and Health Sciences, Universiti Putra Malaysia, Serdang, Selangor, Malaysia.

Received: 7 April 2012 Accepted: 14 September 2012 Published: 18 September 2012

\section{References}

1. Gamoh S, Hashimoto M, Hossain S, Masumura S: Chronic administration of docosahexaenoic acid improves the performance of a radial arm maze task in aged rats. Clin Exp Pharmacol Physiol 2001, 28:266-270.

2. Birberg-thornberg U, Karlsson T, Gustafsson PA, Duche K: Nutrition and theory of mind -The role of polyunsaturated fatty acids (PUFA) in the development of theory of mind. Prostaglandins, Leukotrienes and Essential Fatty Acids 2006, 75:33-41.

3. Su HM: Mechanisms of $n-3$ fatty acid-mediated development and maintenance of learning memory performance. J Nutr Biochem 2010, 21:364-373

4. Noaghiul S, Hibbeln JR: Cross-national comparisons of seafood consumption and rates of bipolar disorders. Am J Psychiatry 2003, 160:2222-2227.

5. Hooijmans CR, Kiliaan AJ: Fatty acids, lipid metabolism and Alzheimer pathology. Eur J Pharmacol 2008, 585:176-196.

6. Grammas P, Yamada M, Zlokovic B: The cerebromicrovasculature: a key player in the pathogenesis of Alzheimer's disease. J Alzheimers Dis 2002, 4:217-223.

7. Kalaria RN: The blood-brain barrier and cerebrovascular pathology in Alzheimer's disease. Ann N. Y. Acad Sci 1999, 893:113-125.

8. Muller M, Grobbee DE, Aleman A, Bots M, van der Schouw YT: Cardiovascular disease and cognitive performance in middle-aged and elderly men. Atherosclerosis 2007, 190:143-149.

9. Privitera GJ, Zavala AR, Federico S, Sotak KL: High fat diet intake during pre and periadolescence impairs learning of a conditioned place preference in adulthood. Behav Brain Funct 2011, 7:21.

10. Yehuda S: Omega-6/omega-3 ratio and brain-related functions. World Rev Nutr Diet 2003, 92:37-56.

11. Yehuda S, Rabinovitz S, Carasso RL, Mostofsky DI: Fatty acids and brain peptides. Peptides 1998, 19:407-419.

12. Yehuda S, Rabinovitz S, Mostofsky DI: Essential fatty acids and the brain: From infancy to aging. Am J Clin Nutri 2005, 26:98-102.

13. Heron DS, Shinitzky M, Hershkowitz M, Samuel D: Lipid fluidity markedly modulates the binding of serotonin to mouse brain membranes. PNAS 1980, 77:7463-7467.

14. Moreno S, Farioli-Vecchioli S, Ceru MP: Immunolocalization of peroxisome proliferatoractivated receptors and retinoid $\mathrm{x}$ receptors in the adult rat CNS. Neuroscience 2004, 123:131-145.

15. Berger J, Moller DE: The mechanisms of action of PPARs. Annu Rev Med 2002, 53:409-435.

16. Schoonjans K, Staels B, Auwerx J: The peroxisome proliferator activated receptors (PPARs) and their effects on lipid metabolism and adipocyte differentiation. Biochim Biophys Acta 1996, 1302:93-109.
17. Osmundsen H, Bremer J, Pedersen Jl: Metabolic aspects of peroxisomal B-oxidation. Biochim Biophys Acta 1991, 1085:141-158.

18. Keller H, Dreyer C, Medin J, Mahfoudi A, Ozato K, Wahli W: Fatty acids and retinoids control lipid metabolism through activation of peroxisome proliferator-activated receptor-retinoid $\mathrm{X}$ receptor heterodimers. Proc Natl Acad Sci U.S.A. 1993, 90:2160-2164.

19. Farioli-Vecchioli S, Moreno S, Ceru MP: Immunocytochemical localization of acyl-CoA oxidase in the rat central nervous system. J Neurocytol 2001, 30:21-33.

20. Pathan AR, Gaikwad AB, Viswanad B, Ramarao P: Rosiglitazone attenuates the cognitive deficits induced by high fat diet feeding in rats. Eur J Pharmacol 2008, 589:176-179.

21. Deplanque D: Cell protection through PPAR nuclear receptor activation. Therapie 2004, 59:25-29.

22. Rinwa P, Kaur B, Jaggi AS, Singh N: Involvement of PPAR-gamma in curcumin-mediated beneficial effects in experimental dementia. NaunynSchmied Arch Pharmacol 2010, 381:529-539.

23. Yasar S, Mazzola C, Medalie J, Scherma M, Panlilio L, Cadet JL, Goldberg S: Fatty acid amide hydrolase inhibition enhances learning and memory through activation of ppar-alpha nuclear receptors. Learn Mem 2009, 16:332-337.

24. Michaud S, Renier G: Direct regulatory effect of fatty acids on macrophage lipoprotein lipase: potential role of PPARs. Diabetes 2001, 50:660-666.

25. Selvaraj RK, Shanmugasundaram R, Klasing KC: Effects of dietary lutein and PUFA on PPAR and RXR isomer expression in chickens during an inflammatory response. Comp Biochem Physiol A Mol Integr Physiol 2010, 157:198-203.

26. Vorhees $\mathrm{CV}$, Williams MT: Morris water maze: procedures for assessing spatial and related forms of learning and memory. Nat Protoc 2006, 1:848-858.

27. Rudkowska I, Garenc C, Couture P, Vohl MC: Omega-3 fatty acids regulate gene expression levels differently in subjects carrying the PPARa L162V polymorphism. Genes Nutr 2009, 4:199-205.

28. Josselyn SA, Nguyen PV: CREB, synapses and memory disorders: past progress and future challenges. Curr Drug Targets CNS Neurol Disord 2005 4:481-497.

29. Kaplinskyi SP, Shysh AM, Nahibin VS, Dosenko V, Klimashevskyi VM, Moibenko OO: Omega-3 polyunsaturated fatty acids stimulate the expression of PPAR target genes. Fiziol Zh 2009, 55:37-43.

30. Folch J, Lees M, Sloane Stanely GH: A simple method for the isolation and purification of total lipides from animal tissues. J Biol Chem 1957, 226:497-509.

31. Rajion MA, McLean JG, Cahill RN: Essential Fatty Acids in the Fetal and Newborn Lamb. Aust J Biol Sci 1985, 38(1):33-40.

32. Pfaffl MW: A new mathematical model for relative quantification in realtime RT-PCR. Nucleic Acids Res 2001, 29:2002-2007.

\section{doi:10.1186/1471-2202-13-109}

Cite this article as: Hajjar et al.: Omega 3 polyunsaturated fatty acid improves spatial learning and hippocampal Peroxisome Proliferator Activated Receptors (PPARa and PPARY) gene expression in rats. BMC Neuroscience 2012 13:109.

\section{Submit your next manuscript to BioMed Central and take full advantage of:}

- Convenient online submission

- Thorough peer review

- No space constraints or color figure charges

- Immediate publication on acceptance

- Inclusion in PubMed, CAS, Scopus and Google Scholar

- Research which is freely available for redistribution 